\title{
Macro e micro regulações da/na escola: avaliações externas em foco
}

\author{
Macro and micro regulations of/at school: focus on external evaluations
}

\author{
Renata Maria Moschen Nascente* \\ Universidade Federal de São Carlos \\ Celso Luiz Aparecido Conti** \\ Universidade Federal de São Carlos \\ Emília Freitas de Lima*** \\ Universidade Federal de São Carlos
}

Resumo O objetivo é analisar as visões de um grupo de diretoras acerca dos efeitos das avaliações externas no cotidiano escolar, que expressavam as formas pelas quais elas se apropriavam dessas macro regulações, traduzindo-as em micro regulações que compunham a organização de suas escolas. O texto se baseia em uma pesquisa qualitativa e exploratória realizada com 65 diretoras de escolas públicas do estado de São Paulo. $\mathrm{O}$ instrumento foi um questionário on line respondido quando as diretoras estavam participando de um curso de especialização oferecido por uma universidade pública, em convênio com o MEC, na Modalidade a Distância. A tematização dos dados evidenciou que as micro regulações podem ter um caráter de resistência, ampliando o escopo da autonomia da escola, ou, ao contrário, reacionário, fortalecendo a lógica das regulações externas.

PALAVRAS-ChAVE: Avaliações externas; Diretoras de escola; Micro regulações.

\begin{abstract}
The aim is to analyze the visions of a group of principals on external evaluation effects in school routines, which expressed the ways they incorporated such macro regulations, translating them into micro regulations that composed the organization of their schools. The text is based on a qualitative and exploratory investigation carried out with 65 public school principals at the state of São Paulo. The instrument was a questionnaire answered by the principals when participating in an on line specialization course offered by the Education Ministry, managed by a public university. The theoretical discussion of the data have evidenced that the micro regulations may have a resistance character, broadening school autonomy scope, or, on the contrary, a reactionary one, enhancing the external regulations logic.
\end{abstract}

KEYWORDS: External evaluations; School principals; Micro regulations. 


\section{Introdução}

Este artigo tem como objetivo analisar e discutir alguns dos dados levantados em uma pesquisa qualitativa e exploratória (BOGDAN; BIKLEN, 2010) realizada com 65 diretoras de escola ${ }^{1}$. O instrumento utilizado foi um questionário online aplicado quando essas diretoras estavam participando de um curso de especialização oferecido por uma universidade pública, em convênio com o MEC, na modalidade de Educação a Distância. O questionário tinha como finalidade evidenciar as visões das diretoras sobre implementações de algumas políticas públicas educacionais em suas escolas. Neste texto, especificamente, focalizamos as visões das diretoras acerca as avaliações externas, que têm se constituído nas últimas duas décadas em instrumentos de regulação bastante influentes nas escolas públicas de ensino fundamental e médio.

Partimos do pressuposto de que existe uma relação dinâmica entre as visões das diretoras, suas respectivas formações e o exercício efetivo de suas funções, sendo que essas dimensões caminham juntas, intrinsecamente ligadas, ao longo de suas vidas profissionais (IMBERNÓN, 2005; 2009). Assim, entendemos que algumas das questões respondidas pelas diretoras podem refletir tanto seus desenvolvimentos profissionais, quanto o trabalho pedagógico e administrativo realizado por elas em suas respectivas escolas, mormente no que se refere à organização escolar, por esta ser, por excelência, uma atribuição da direção.

Portanto, as visões das diretoras sobre as avaliações externas poderiam ser consideradas como bases sobre as quais elas se apropriam e interpretam essas políticas públicas, tratadas aqui no plural por se tratarem tanto de avaliações administradas pelo governo federal como pelo estadual.

Compreendendo assim as avaliações externas como macro regulações e que as visões das diretoras sobre elas são preponderantes no desenvolvendo das micro regulações, que são procedimentos que possibilitam as aplicações dessas políticas nas escolas, nossa questão norteadora, neste artigo, diz respeito a quais seriam suas visões sobre as avaliações externas. Nossa hipótese é que essas visões são influenciadas pelas formações das diretoras e pelo próprio cotidiano escolar, marcadas por um embate entre os campos público e privado (SILVA JR., 2015). Dessa forma, as visões das diretoras seriam preponderantes nas micro regulações, constituidoras das diferentes organizações escolares, que são as apropriações das regras impostas pela legislação e políticas públicas, suas interpretações, reinvenções e atualizações, dando origem a formas de organização escolar instituídas pelos sistemas de ensino e, ao mesmo tempo, instituintes por parte das escolas (LIMA, 2011; BOTLER, 2015).

A discussão das imbricações inerentes ao relacionamento entre macro e micro regulações, com foco nas avaliações externas, é relevante na medida em que pode contribuir para o desenvolvimento de uma crítica às políticas públicas, considerandose o efetivo cumprimento de seus objetivos, isto é, quando chegam e ganham vida nas escolas, influenciando, principalmente sua organização. Além disso, talvez seja possível, por meio dessa análise, que diretoras de escola e equipes gestoras desenvolvam uma melhor compreensão da sua capacidade de influência, por meio das micro regulaçóes, ampliando assim a autonomia da escola, para além dos seus campos de autonomia decretada (BARROSO, 1996). 
Nóvoa (1999) nos apresenta a ideia de que para compreender como as escolas se organizam é necessário entender como seus atores, principalmente as equipes de direção, jogam um jogo de intermediação entre os sistemas de ensino, criadores e/ ou executores de regulações externas que pressionam as escolas a tomar determinados rumos, e a comunidade escolar. Esse jogo é disputado com base nas micro regulaçôes, regras e procedimentos criados nas escolas para tentar tanto corresponder aos objetivos dos sistemas como de seus partícipes. Trata-se de um jogo de forças que nas escolas é liderado pelas diretoras, por mecanismos próprios da democracia representativa, de negociação, isto é, de convencimento dos membros dos colegiados escolares de cursos de ação previamente elaborados pelas equipes de administração das escolas, diferentemente de mecanismos de deliberação, nos quais as pautas discutidas seriam propostas e acordadas pelos diferentes segmentos, próprios da democracia como cosmovisão, como nos apresenta Toro (2015).

Essa maneira de entender o jogo de forças no interior da escola fundamenta-se cada vez mais na ampliação da autonomia decretada nas últimas três décadas (BARROSO, 1996). Essa autonomia, ainda que limitada, tem se mostrado importante no desenvolvimento de diversos aspectos necessários à democratização e à qualificação da educação escolar. É o caso por exemplo, da ampliação dos tempos e espaços de participação das comunidades nas escolas e a apropriação de currículos, nacional e/ou regional em termos locais, modalidades de micro regulação vigentes nas escolas, cotidianamente se constituindo repletas de ambiguidades e incertezas (SILVA, 2003; CASTIANO, 2005-2006).

Nesse sentido, as equipes escolares parecem estar imbuídas do objetivo de se apropriarem de forma frutífera dos resultados das avaliações externas, apropriação que em si mesma é uma micro regulação. Segundo Werle e Audino (2015, p.131), no espaço escolar relativamente autônomo, por meio de micro regulaçôes "poderá ocorrer a produção de regras e de quadros de referência por processos de apropriação que sempre são únicos, localizados e contingentes". As micro regulaçôes são identificáveis tanto na zona de visibilidade como na de invisibilidade (NOVOA, 1999, p. 30), isto é, concretizam-se em manifestações verbais, visuais e atitudinais no cotidiano escolar e também nas concepções dos diferentes integrantes da escola.

Abdian e Oliveira (2015, p. 181), ao investigarem as relações entre gestão e qualidade da educação em escolas estaduais paulistas, apontaram que o conceito de qualidade é polissêmico e que seria composto por três elementos fundamentais: garantia de acesso, controle de fluxo escolar e desempenho em testes de larga escala. Entendemos que esses três significados de qualidade poderiam ser identificados como áreas da educação escolar a serem reguladas pelo Estado por meio dos sistemas de ensino, tendo as avaliações externas um papel de destaque nesse processo. Estendendo um pouco esse entendimento, podemos conceber que o Estado passou a legislar e a produzir políticas públicas objetivando a regulação dos sistemas educacionais, que, por sua vez, reproduzem, interpretam e, quando possível e necessário, adaptam esses instrumentos para regularem as escolas de suas respectivas redes (LIMA, 2011). 
Por isso, as formas como as escolas se organizam tem a ver com os processos de micro regulaçôes. Por outro lado, há as variáveis culturais existentes no meio social no qual a escola está imersa (NÓVOA, 1999). Tanto as políticas como essas variáveis, que exercem pressões sobre a escola, são interpretadas e recriadas por seus atores (LIMA, 2011). Nesse processo há que se ter clareza da fragilidade dos sistemas de ensino, e, consequentemente, de suas políticas (SILVA JR., 2015), tendo em vista as variáveis culturais com as quais a escola inescapavelmente tem que lidar.

Ao tentar explicitar quais são as macro regulações mais proeminentes na organização das escolas públicas de educação básica atualmente em nosso país, nos deparamos ainda com um aspecto fulcral: essas regulações exercem suas influências nas escolas frequentemente de maneira imbricada e contraditória.

Costa, Lima e Leite (2015) explicitam uma dessas imbricações, a saber, os discursos sobre a inclusão, transmutado em diversas políticas e determinações legais e a perspectiva do mérito, baseada nas avaliações externas, que em última instância individualizam a responsabilidade pelos baixos índices de desempenho dos alunos em suas respectivas unidades escolares. As autoras demarcam a iminente contradição entre essas duas políticas na realidade escolar, uma vez que a busca da elevação dos índices de rendimento dos alunos leva quase que automaticamente a um processo de seleção de quais são os alunos desejáveis, com perfil adequado ao alcance das metas estabelecidas pelo sistema, levando à exclusão de quaisquer estudantes que ameacem esse objetivo, tais como aqueles que apresentam "dificuldades de aprendizagem", necessidades especiais, que pertencem a famílias não convencionais e/ou que se encontram em situação de conflito com a lei.

Essas duas políticas, do mérito e da inclusão (COSTA; LIMA; LEITE, 2015), são interpretadas pelas escolas que as atualizam e as praticam de acordo com suas próprias culturas, cada uma estando mais aberta ou não a incluir estudantes, por exemplo, em regime de Liberdade Assistida - isto é, cumprindo alguma medida judicialmente estabelecida - ou com necessidades especiais, o que pode estar relacionado inclusive à estrutura física do prédio escolar e à disponibilidade de funcionários para apoiar essa acolhida. Já em outras escolas, os supostos benefícios do alcance das metas estabelecidas pelas políticas de mérito, tais como os bônus, podem levá-las a se organizarem de forma refratária ao acolhimento de jovens vistos como não capazes de contribuir com esse objetivo.

De acordo com esse raciocínio, entendemos as diretoras de escola como mediadoras entre as macro e micro regulaçôes, em processos de apropriação, autoria e ação. Por isso, parece-nos importante compreender suas visões sobre as macro regulaçôes, porque elas podem prover insights sobre como elas realmente chegam aos estudantes, na forma de micro regulações que organizam as escolas.

A seguir apresentamos e discutimos os dados relativos às visões das diretoras sobre as práticas administrativas e pedagógicas em suas respectivas escolas tributárias das avaliações externas. 


\section{Visões das diretoras sobre as avaliações externas}

Thiesen (2014), Abdian e Oliveira (2015) destacam que no atual contexto de democratização da escola pública, as avaliações externas como políticas públicas contradizem esse processo nele próprio. Isto é, pretensamente gestões escolares democráticas, baseadas na autonomia e na participação, deveriam ser gradativamente implantadas juntamente com práticas de ranqueamento meritocrático, fundamentadas principalmente em índices de rendimento mensuráveis, como questiona Thiesen (2014, p. 196): "como articular gestão democrática, participativa, coletiva e colaborativa para atingir finalidades seletivas, restritivas e competitivas?”. Para o autor:

[...] há um discurso institucional produzido e disseminado por meio de diretrizes curriculares oficiais e pela mass media que fagocita os conceitos originados, em geral, nas teorias de esquerda, os recontextualiza e apresenta como sendo princípios seus. Assim, expressões como cidadania, autonomia, direitos sociais, direitos humanos e inclusão, por exemplo, são frequentemente encontradas nos textos orais e escritos. O que se vê são discursos liberais mascarados com alguma panfletagem de tonalidade democrática (THIESEN, 2014, p. 194).

Portanto, do ponto de vista das políticas públicas, parece se consolidar um movimento de mascaramento das avaliações externas, representando-as como parte de uma gestão escolar supostamente democrática e de qualidade. Esse mascaramento é acionado pelos próprios documentos oficiais, e reforçado pela mídia. Esses meios repetidamente apregoam a existência de uma ligação intrínseca entre resultados obtidos por escolas e sistemas nas avaliações externas e certa concepção de qualidade da educação, vinculada a um ideário neoliberal no qual essa qualidade refere-se à capacidade das escolas de preparem estudantes das camadas populares para atender às necessidades do mercado de trabalho, principalmente em funções técnicas. Então, o baixo rendimento de estudantes em testes que normalmente medem conhecimentos nas áreas de Língua Portuguesa e Matemática seriam indicadores de deficiências que comprometeriam o desempenho futuro dos estudantes, trabalhadores em potencial.

Quando as avaliações externas adentram a escola, com seu aparato ideológico explicativo, constituído por manuais de apoio e aplicação, orientações técnicas e determinações de como, quando e por quem todos os procedimentos que as cercam devem ser colocados em ação, resta muito pouco tempo e energia às equipes escolares para refletir por quem e para quem essas avaliações são elaboradas e aplicadas. Mormente engendradas por organismos internacionais por meio de instituições ligadas ao terceiro setor em uma perspectiva neoliberal de standartização (THIESEN, 2014), elas são incorporadas ao cotidiano escolar em um instrumental constituidor de sua organização nos campos administrativo e pedagógico.

Apesar desse fosso entre gestão democrática, qualidade social da educação ${ }^{2}$ e as avaliações externas, não se pode negar a possibilidade das escolas de virarem esse jogo a seu favor, isto é, de conseguirem interpretar e aplicar essa macro regulação de forma a contribuir para aprendizagens significativas de seus estudantes. Se não acreditássemos na escola, daríamos tudo o que tem realizado como perdido, o que não nos parece o caso, 
[...] a escola apresenta uma face institucional que prioriza o cumprimento de uma determinada função social, legitimada historicamente. Esta face construiu conjuntamente uma forma de organização administrativa caracterizada por inúmeros aspectos, entre eles, a hierarquização, a centralização de poder e a reprodução de normas. [...] Entretanto, a escola, constituída por seres humanos políticos, apresenta a potencialidade de transformação, de construção de identidade e modos próprios de funcionamento. Pensar a avaliação (da aprendizagem, em larga escala e institucional) nesta perspectiva ganha um tom diferente. [...]. Neste sentido, é fundamental conhecermos e analisarmos como as organizações escolares são construídas e interagem com as políticas governamentais nos diferentes âmbitos (ABDIAN; OLIVEIRA, 2015, p. 179).

A seguir apresentamos as visões das diretoras no que se refere às avaliações externas em suas respectivas escolas. Do grupo de 65 diretoras respondentes do questionário, 40 afirmaram que as avaliações externas interferem diretamente em seu trabalho; 19 responderam que não há essa interferência; duas eram diretoras de escolas de educação infantil e somente uma delas respondeu à questão relativa a essa interferência; e, finalmente, quatro diretoras não responderam a essa questão. Das 41 diretoras que afirmaram haver interferência das avaliações externas em seu trabalho, 38 consideraram essa interferência como positiva e apenas três consideraram-na negativa, sendo que as que consideraram negativa a interferência não explicaram as razões dessa visão.

Não obstante o fato de entendermos que cada direção escolar pode encaminhar diferentemente as demandas postas pelas avaliações externas a que estão sujeitas, em um escopo limitado de autonomia, percebemos pelos excertos das diretoras, a seguir apresentados, que elas consideraram a interferência das avaliações externas como positiva em seu trabalho. Haveria, portanto, a incorporação dessas avaliações em uma perspectiva de mascaramento, isto é, atribuição de características que elas não possuem (THIESEN, 2014).

A seguir passaremos a discutir o conjunto dos excertos que nos pareceram ser expressões das visões das diretoras sobre como as relações entre macro e micro regulações se revelam nos dados relativos às avaliações externas, norteando o planejamento escolar, o trabalho docente, as aprendizagens estabelecendo noções do que seria qualidade de ensino e os objetivos a serem atingidos pelos estudantes.

Uma das possíveis funções das avaliações externas para três das diretoras seria o estimulo para que estudantes e equipe escolar se esforçassem para atingir as metas estabelecidas, auxiliando estudantes, professores e comunidades em diversos aspectos. Para elas, as avaliações:

- Estimulam o cumprimento das metas propostas. Investimentos de recursos pedagógicos;

- Favorecem o trabalho na escola com indicadores dos resultados analisados tabulados, há planos de melhoria e motivação para aprendizagem;

- Provocam a necessidade de discutir, conhecer e ajudar no desempenho do aluno, auxiliando os professores e a comunidade; 
- Permitem uma reflexão e tomada de decisões mais coerentes;

- Ajudam na análise dos indicadores de evasão, aprovação/reprovação, análise de recursos disponíveis;

- Favorecem o trabalho na escola porque incentivam os alunos e professores a se destacarem cada vez mais em seus aprendizados e ensinamentos (quando positivos os resultados), refletindo uma educação de qualidade.

Este último excerto, além de demonstrar a visão das avaliações como motivadoras de professoras e estudantes, indica outra tendência, a das avaliaçóes externas como indicativas da qualidade da educação oferecida em suas escolas.

- Pelos resultados pode-se medir o nível da qualidade da educação, norteando o trabalho de planejamento e replanejamento das práticas pedagógicas.

- Elas indicam o caminho para a melhoria da qualidade de ensino.

- Elas fazem com que a equipe se mantenha focada na qualidade de ensino, recentemente também passamos a envolver as famílias que também estão se sentindo responsáveis pelos rendimentos.

Se para as diretoras os resultados produzidos pelas avaliações externas seriam indicadores da qualidade da educação oferecida pelas escolas, talvez seja possível inferir que a qualidade a que se referem seja justamente aquela que se identifica com a administração gerencialista, que vem sendo implementada por muitas das secretarias de educação nas escolas (WERLE; AUDINO, 2015; ABDIAN; OLIVEIRA, 2015).

Além da questão da qualidade, também podem ser observadas evidências relativas à responsabilização das famílias e das equipes em relação ao rendimento escolar expresso nas avaliações (AFONSO, 2003; DUBET, 2004; THIN, 2006). Há que se questionar qual a condição das famílias de participar em processos de ensino e aprendizagem voltados quase que exclusivamente para resultados nas avaliações externas. Se é que possa existir essa participação, ela poderia ser considerada genuína dentro dos princípios da gestão democrática, ou manipulada, objetivando satisfazer aos objetivos do sistema de ensino e da equipe escolar? Quem são os reais beneficiários de resultados positivos nessas avaliações, se é que existe algum além do próprio sistema capitalista no qual a escola está inserida?

O escopo das avaliações externas como micro regulações do trabalho nas escolas, particularmente no que diz respeito ao das diretoras, revela como tais avaliações vêm ocupando um lugar de destaque entre as atividades escolares. As escolas são organizadas e administradas pelas diretoras para que estudantes, professoras e famílias trabalhem para a elevação dos níveis de rendimento nas avaliações externas, cujo feedback deve retroalimentar o ensino, a aprendizagem, a administração. Trata-se de uma regulação que abrange todo o ano letivo, antes, durante e após a realização das avaliações. Ou seja, as avaliações externas adentram as escolas, regulando-as de diferentes maneiras, direcionando todos os atores, tempos e ações escolares na busca de objetivos para satisfazer demandas de uma sociedade cada vez mais competitiva, meritocrática e neoliberal, apesar do discurso da inclusão e da democratização (BARROSO, 2005). Portanto o trabalho nas escolas passa a ser regulado pelas avaliações, e não como de- 
veria ser: as avaliações servindo às escolas que se organizariam em função de objetivos educacionais por elas decididos.

Outra perspectiva emergente nos excertos das diretoras é a de que as avaliações externas teriam um papel importante no currículo praticado pelas escolas. As avaliações:

- Fazem interagir melhor com o currículo e a real prática em sala de aula. E assim posso trabalhar a favor dos índices.

- Ajudam a adaptar o currículo, o planejamento, nos direcionando às dificuldades apresentadas a fim de saná-las.

- Contribuem para reorganização do currículo e organização de novas estratégias de ensino.

- Direcionam o trabalho pedagógico conforme o currículo do Estado de São Paulo.

O primeiro excerto coloca as avaliações como interlocutoras entre o currículo e a real prática das salas de aula: o currículo oficial, qualquer que seja ele, deve ser executado pelas escolas, na perspectiva apresentada. Inversamente, poderíamos supor que, sem as avaliações externas, currículo oficial e o currículo executado nas salas de aula caminhariam em diferentes direções. Outro aspecto interessante nesse excerto é como a diretora divide o trabalho a ser realizado com base nas avaliações, dando a entender que a questão curricular e pedagógica é para ser cuidada pelas professoras. Já a parte dela, da direção, seria diretamente ligada à elevação dos índices, supostamente administrando para que isso ocorresse. Ora, é inevitável a visualização do trabalho na escola por meio da metáfora da linha de montagem. Trata-se de uma visão de currículo bastante tradicional, originada nos EUA no início do século passado, cujo campo especializado surgiu da necessidade de educar as massas para o mercado de trabalho (SILVA, 2003).

Nos segundo e terceiro excertos, as diretoras atribuem outro papel importante às avaliações, em relação ao currículo, que precisa ser adaptado para sanar as dificuldades de estudantes. Isso revela um aspecto de apropriação tanto do currículo como das avaliações na perspectiva de micro regulações. As avaliações seriam, assim, as organizadoras do currículo na escola, justificando a existência e a prática de um determinado currículo. Trata-se novamente de uma inversão, pois as decisões do que e como ensinar deveriam preceder a avaliação, e esta deveria retroalimentar a escola no redirecionamento do currículo.

Finalmente, o quarto excerto demonstra a assunção da relação entre as avaliações externas e o currículo oficial da rede à qual pertence a escola. A diretora parece jogar o jogo proposto por aqueles que pensam tanto as avaliações quanto o currículo; e nesse jogo, a escola é vista como executora de um currículo e de uma avaliação estabelecida pelo estado avaliador (SCHNEIDER, M.P.; ROSTIROLA FREITAS, 2015; FREITAS et.al., 2011). 
Outro aspecto marcante apresentado pelas diretoras, e que indica as avaliações externas como micro regulações da organização escolar, é a relação entre elas, o planejamento escolar, o trabalho docente e as aprendizagens dos estudantes, como indicam os seguintes excertos:

- Análise dos resultados [das avaliações] serve de parâmetros para novas ações pedagógicas.

- As avaliações nos mostram o que é desejado de um estudante ao final do ciclo do fundamental - anos iniciais e a partir daí analisamos os resultados e procuramos interpretar os dados de modo que favoreça o trabalho pedagógico da escola e o planejamento de ações para melhorar o desempenho discente.

- Elas dão informações e subsídios para direcionar o trabalho pedagógico.

- Nos ajudam a realizar uma avaliação de nosso trabalho e propor ações para alcançarmos melhorias.

- Possibilitam uma reavaliação da prática da docência, bem como o planejamento de ações com vista à melhoria.

- Por ocasião das avaliações externas, o grupo se debruça sobre modelos de questões dadas anteriormente preparando os alunos; os pais participam também, comparecendo também às reuniões de organização dos dias de prova e um mini projeto é montado para atendimento especial.

Nestes excertos ficaram fortemente demarcadas as ideias de desempenho e de parâmetros, evidenciando que há parâmetros de desempenho a serem alcançados, como bem pontuou Thiesen (2014).

O último excerto demonstra a força das avaliações externas como instrumentos de regulação, pois as escolas criam outras avaliações, que parecem reger suas vidas, para tentar corresponder às demandas das próprias avaliações.

No que diz respeito ao planejamento escolar, os excertos explicitam o seguinte:

- Os resultados servem de objeto de reflexão sobre a prática educativa e norteiam o planejamento.

- Elas ajudam a conhecer o perfil da escola, dos alunos e quais as dificuldades apresentadas no seu percurso de ensino e aprendizagem.

- Com os resultados é possível refletir juntos com a comunidade sobre os aspectos que podem estar associados aos resultados apresentados. Desse modo colabora no planejamento das ações que visem à melhoria desses desempenhos.

- Favorecem o trabalho na escola. As avaliações nos ajudam a elencar pontos que ainda precisam ser mais trabalhados, onde nossos alunos não conseguiram atingir níveis satisfatórios. Também ajudam a indicar as áreas de evolução no ensino e aprendizagem e como caminhar para mantê-las.

- Elas nos dão um norte para replanejar o método de ensino.

- Através dos resultados dessas avaliações temos uma amostra de como vai o ensino e aprendizagem na escola. 
Os excertos parecem reproduzir o discurso oficial, em uma lógica de elaboração, execução e reprodução, um processo de mediação entre as secretarias de educação e as escolas, realizado pelas diretoras. Assim, destaca-se a ideia de que as avaliações externas poderiam fornecer retornos em relação às aprendizagens dos estudantes. Essa ideia pode ter sua origem também em discursos acadêmicos sobre avaliações contínuas e formativas aos quais os profissionais da educação básica vêm sendo submetidos tanto nos cursos de formação inicial como continuada (ESTRELA; NÓVOA, 1999; HOFFMANN, 1996; LUCKESI, 1996). O problema a ser analisado refere-se às diferenças fundamentais entre as avaliações elaboradas e realizadas internamente nas e pelas escolas e as avaliações externas. Quando uma professora aplica uma avaliação em sua sala de aula provavelmente conhece razoavelmente como vêm se desenvolvendo cada um dos estudantes, e o resultado da avaliação lhe permite obter outros elementos úteis para sanar dificuldades, rever conteúdos e promover novas aprendizagens. As informações que podem ser colhidas por meio de uma avaliação externa são de outra natureza, podem aferir tendências gerais, mas não são passíveis de darem informações nem sobre uma única escola, quanto mais uma sala de aula, uma professora, e/ou um estudante.

Apesar de somente dois excertos referirem-se especificamente à administração escolar, ela esteve subliminarmente presente em toda nossa discussão em torno dos excertos das diretoras acerca de como as avaliações externas seriam benéficas às escolas. Para duas das diretoras, a relação específica entre avaliações externas e administração escolar confirma nossa hipótese de que ao adentrar as escolas essas avaliações e seus respectivos aparatos são transmutados em micro regulações, que podem servir tanto aos propósitos das próprias avaliações como a outros, dos partícipes de cada escola.

- [As avaliações] norteiam as ações gestoras e docentes para o alcance dos resultados educacionais e aprendizagem dos alunos.

- Os resultados servem para revermos alguns pontos nevrálgicos da escola.

Chamou ainda particularmente a atenção um último excerto, referente a uma diretora de uma escola de educação infantil. Apesar de não estar incluída em situações de avaliação externa, a cultura avaliativa parece já ter chegado até lá:

- Apesar da escola não participar das avaliações externas pela idade/série dos alunos, sabemos que somos a base da aprendizagem, por isso realizamos avaliações internas e acompanhamos os índices do município.

\section{Algumas considerações}

Como foi demonstrado na tematização dos dados originados nas questões respondidas pelas diretoras, as avaliações externas constituem-se em micro regulações que de algum modo organizam as escolas.

No campo das micro regulações, as indicações que temos é que tanto elas podem auxiliar no cumprimento dos objetivos estabelecidos pelo Estado neoliberal, meritocrático e avaliador, como também podem servir para virar esse jogo, atendendo aos reais e necessários objetivos de seus estudantes, famílias e comunidades. Assim, supomos que as micro regulações podem ter um caráter de resistência, ampliando a 
autonomia construída da escola, ou, ao contrário, reacionário, fortalecendo a lógica da regulação externa. Portanto não se pode atribuir às micro regulações um caráter positivo ou negativo, tudo vai depender de como elas são elaboradas em cada contexto escolar, considerando que as micro regulações guardam em si os germes das macro regulações, sem as quais simplesmente não existiriam.

As reações e resistências das escolas ainda se manifestam timidamente, nos parâmetros de uma autonomia outorgada pelos sistemas, que não permite grandes voos, mas também não as sufoca totalmente. Portanto, precisamos compreender melhor como as políticas públicas do atual Estado brasileiro influenciam as escolas e como elas são ressignificadas de dentro para fora, em seus interiores. Essa compreensão parece estar ainda em um estágio inicial, pois no campo das políticas públicas aparentemente os estudos têm se concentrado mais nos aspectos macro, isso é nas formulações e estratégias de intervenção nos sistemas e nas escolas, restando um vasto campo de pesquisa a ser explorado no que diz respeito às políticas públicas em ação nas escolas. Este é justamente o interesse que levou à elaboração deste texto e que, esperamos, nos leve a aprofundar pesquisas e escrever outros, pois como nos alerta Silva Jr. (2015), muito temos que caminhar para a elaboração de uma teoria da escola pública no Brasil.

\section{Referências}

ABDIAN, G. Z.; OLIVEIRA, M. E. N. Gestão e qualidade da educação de escolas estaduais paulistas no contexto dos indicadores de desempenho. Revista Brasileira de Política e Administração da Educação, Recife, v. 31, n. 1; p. 177-195, jan./abr. 2015.

AFONSO, A. J. Escola pública, gerencialismo e accountability. Página da educação, Porto, n. 12, p. 01-2, ago/set. 2003. Disponível em: <http://www.apagina.pt.>. Acesso em 07 jul. 2015.

BARROSO, J. O estudo da escola. Porto: Porto Editores, 1996.

. O Estado, a educação e a regulação das políticas públicas. Educação e Sociedade, Campinas, vol. 26, n. 92, p. 725-751, Especial - Out. 2005. Disponível em: <http://www.cedes.unicamp.br>. Acesso em 09. ago. 2016.

BOGDAN, R. C.; BIKLEN, S. K. Investigação qualitativa em educação: uma introdução à teoria e aos métodos. 9 ed. Porto: Porto, 2010,336p.

BOTLER, A. M. H. Repercussões das políticas educacionais na organização escolar. Revista Brasileira de Política e Administração da Educação, Recife, v. 31, n. 1; p. 107-124, jan./abr. 2015.

CASTIANO, J. P. O currículo local como espaço social de coexistência de discursos: estudo de caso nos distritos de báruè, de sussundenga e da cidade de Chimoio - Moçambique. Revista E-Curriculum, São Paulo, v. 1, n. 1, dez. - jul. 2005-2006. Disponível em: <http://www.pucsp. br/ecurriculum>. Acesso em 03. Ago. 2015.

COSTA, E. A. S.; LIMA, M. S. L.; LEITE, M. C. S. A construção da profissionalidade do gestor escolar: concepções e práticas. Revista Brasileira de Política e Administração da Educação, Recife, v. 31, n. 1; p. 65-84, jan./abr. 2015.

DUBET, F. O que é uma escola justa? Cadernos de Pesquisa, v. 34, n. 123, p. 539-555, set./dez. 2004. Disponível em: <www.scielo.br>. Acesso em: 25 jan.2015.

ESTRELA, A.; NÓVOA, A. (Org.). Avaliações em educação: novas perspectivas. Portugal: Porto Editora, 1999. 
FREITAS, L. C. de et.al. Avaliação educacional: caminhando pela contramão. 3 ed. Petrópolis, RJ: Vozes, 2011.

HOFFMANN, J.Avaliação, mito e desafio: uma perspectiva construtivista. 4 ed. Porto Alegre: Mediação, 1996.

IMBERNÓN, F. Formação docente e profissional. 5 ed. São Paulo: Cortez, 2005.

Formação permanente do professorado: novas tendências. São Paulo: Cortez, 2009.

LIMA, L. Para uma abordagem sociológica dos modelos organizacionais de escola pública. In: LIMA, L. A escola como organização educativa. 4 ed. São Paulo: Cortez, 2011, p. 93-115.

LUCKESI, C.C. Avaliação da aprendizagem escolar. São Paulo: Cortez, 1996.

NÓVOA, A. Para uma análise das instituições escolares. In: NÓVOA, A. (Org.). As organizações escolares em análise. 3 ed. Lisboa: Dom Quixote/Portuguesa, 1999, p. 15-43.

SILVA JR., C.A. Para uma teoria da escola pública no Brasil. Marília: M3T Edições e Treinamento, 2015.

SILVA, M.A. Qualidade social da educação pública: algumas aproximações. Cadernos Cedes, Campinas, vol. 29, n. 78, p. 216-226, maio/ago. 2009. Disponível em <http://www.cedes.unicamp.br>. Acesso em: 04. ago. 2016.

SILVA, T. T. Documentos de identidade: uma introdução às teorias de currículo. 2 ed. Belo Horizonte: Autêntica, 2003.

SCHNEIDER , M.P.; ROSTIROLA, C.R. Estado-Avaliador: reflexões sobre sua evolução no Brasil. RBPAE, v. 31, n. 3, p. 493-510, set./dez. 2015.

THIESEN, J. S. Currículo e gestão escolar: territórios de autonomia colocados sob a mira dos standards educacionais. Currículo sem Fronteiras, v. 14, n. 1, p. 192-202, jan./abr. 2014.

THIN, D. Para uma análise das relações entre famílias populares e escola: confrontação entre lógicas socializadoras. Revista Brasileira de Educação, v. 11, n. 32 (maio/ago). 2006, p. 211225. Disponível em <http://www.scielo.br/pdf/rbedu/v11n32/a02v11n32.pdf >. Acesso em: 05. jun. 2015.

TORO, J.B. Educacion para la democracia. CIVICUS/Funredes, Bogotá, s/d. Disponível em: <http://funredes.org/funredes/html/castellano/publicaciones/educdemo.html.> Acesso em: 26 out. 2015.

WERLE, F. O. C.; AUDINO, J. F. Desafios da gestão escolar. Revista Brasileira de Política e Administração da Educação. Recife, v. 31, n. 1; p. 125-144, jan./abr. 2015.

\section{Notas}

\footnotetext{
${ }^{1}$ Referir-nos-emos às diretoras no feminino dada a configuração de gênero dos profissionais da educação básica no Brasil.

${ }^{2}$ Segundo Silva (2009, p. 224) dentre os determinantes externos que contribuem para a qualidade da educação escolar destacam-se os fatores socioeconômicos, socioculturais, financiamento público adequado e compromisso dos gestores centrais. No interior da escola, outros elementos sinalizam a qualidade social da educação, entre eles, a organização do trabalho pedagógico e gestão da escola; os projetos escolares; as formas de interlocução da escola com as famílias; o ambiente saudável; a política de inclusão efetiva; o respeito às diferenças e o diálogo como premissa básica; o trabalho colaborativo e as práticas efetivas de funcionamento dos colegiados e/ou dos conselhos escolares.
} 
* Professora doutora da Universidade Federal de São Carlos, São Carlos, São Paulo, Brasil.

** Professor doutor da Universidade Federal de São Carlos, São Carlos, São Paulo, Brasil.

*** Professora doutora da Universidade Federal de São Carlos, São Carlos, São Paulo, Brasil.

\section{Correspondência}

Renata Maria Moschen Nascente - Universidade Federal de São Carlos, Centro de Educação e Ciências Humanas. Rodovia Washington Luís, Km 235. Jardim Guanabara. CEP: 13565905. São Carlos, São Paulo, Brasil.

E-mail:rmmnascente@gmail.com - celsocon@ufscar.br - eflima281001@gmail.com

Recebido em 20 de outubro de 2016

Aprovado em 15 de fevereiro de 2017 
